\title{
«Que teatro é este?»: \\ Pensamento e processo de \\ Um Museu Vivo de Memórias \\ Pequenas e Esquecidas
}

JOANA CRAVEIRO

Joana Craveiro é doutoranda na Universidade de Roehampton (Reino Unido, ao abrigo de uma bolsa da FCT) e mestre em Encenação pela Royal Scottish Academy of Music and Drama (2004). É docente na Escola Superior de Artes e Design (ESAD.CR) e investigadora afiliada do Instituto de História Contemporânea da Universidade Nova de Lisboa (IHC/FCSH). É directora artística do colectivo Teatro do Vestido, que fundou em 2001.

This article reflects upon the methods and process of the performance Um Museu Vivo de Memórias Pequenas e Esquecidas [A Living Museum of Small and Forgotten Memories], where Joana Craveiro addresses the historical and personal memory of the Portuguese dictatorship (1926-1974), revolution (April 25 th 1974$)$ and revolutionary process (1974-1975). Craveiro gives an account of the authors and works that have inspired A Living Museum, which is built in the interplay of the "archive" and the "repertoire" (Taylor, 2003), concepts used to describe different modes of memory and knowledge transmission, and which the performance bridges. The article further addresses the relationship of the performance with the absence of non-inscription of memories in the public space, as well as the silencing of personal memories, which renders A Living Museum a "space of possibilities": of exchange, remembering, inscription and reconciliation.

MEMORY / POSTMEMORY / ARCHIVE / REPERTOIRE / ORAL HISTORY / RECONCILIATION

\begin{abstract}
A interpelação que serve de título a este artigo decorreu na última apresentação de Um Museu Vivo de Memórias Pequenas e Esquecidas no Festival Internacional de Teatro de Almada, a 6 de Julho de 2015. Um espectador que tinha assistido à estreia mas que não tinha podido ficar então para o debate que decorre no final de cada apresentação de Um Museu Vivo veio expressamente ao último espectáculo para me fazer esta pergunta: «Que teatro é este?» Visivelmente emocionado, este espectador disse-nos que este teatro lhe falava da vida das pessoas, da vida dele. Penso que nenhum de nós conseguiu explicar que teatro era afinal aquele, nem eu própria, que passei desde logo a palavra ao crítico Jorge Louraço Figueira, que moderava o debate.
\end{abstract}




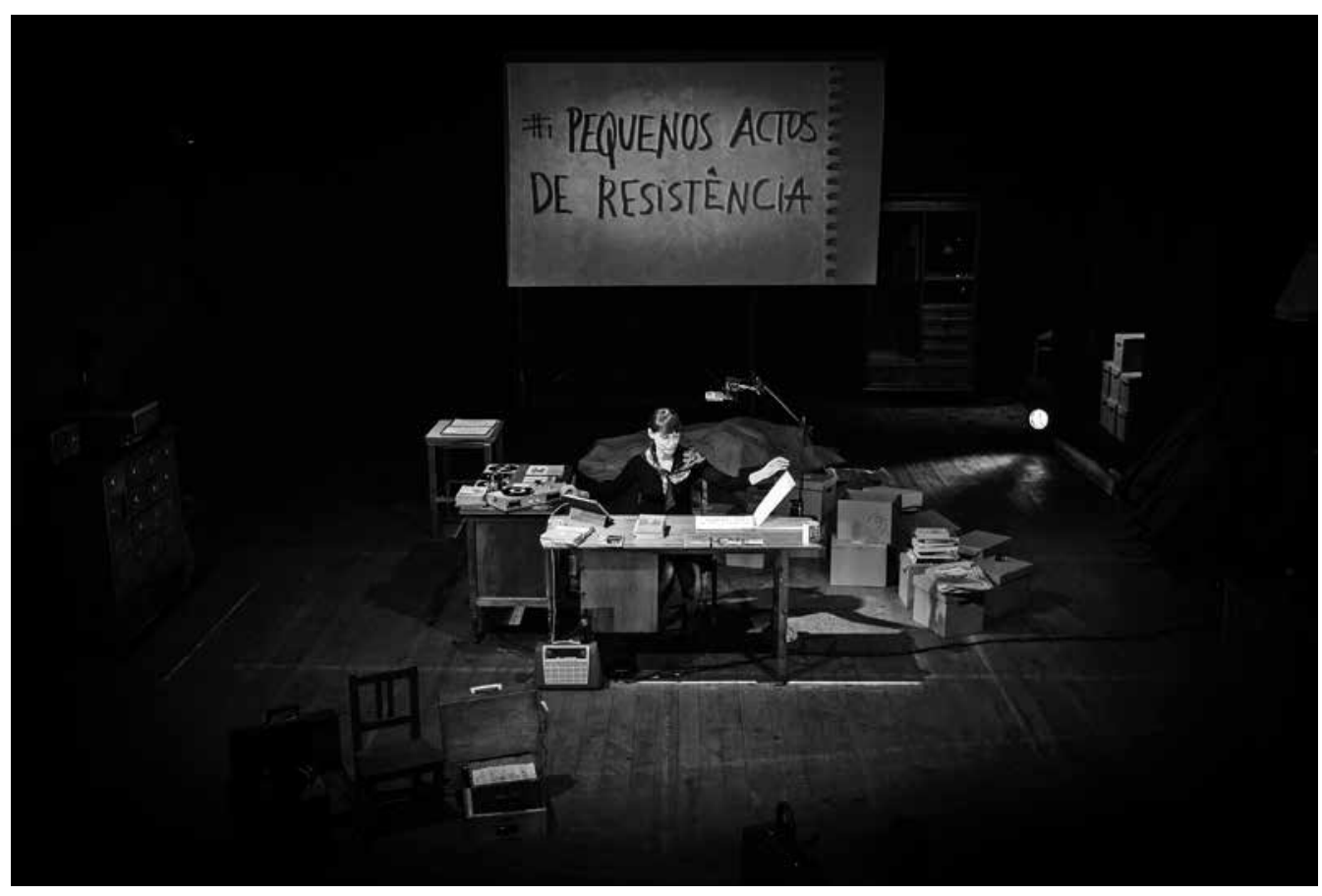

UM MUSEU VIVO DE MEMÓRIAS PEQUENAS E ESQUECIDAS, DE JOANA CRAVEIRO, TEATRO DO VESTIDO, 2015 (JOANA CRAVEIRO) [F] JOÃO TUNA
Atrapalhados, passávamos a palavra uns aos outros, enquanto o homem nos olhava de olhos cheios de histórias - que não chegou a partilhar. Penso que não conseguimos dar resposta, porque não nos relacionámos verdadeiramente (porque não conseguimos?) com a emoção viva e real daquele homem naquele momento e talvez porque responder-lhe não fosse o mais importante. Ele ter vindo fazer a pergunta e o silêncio que se lhe seguiu foi, isso sim, o mais significativo deste teatro, seja qual for o seu tipo.

Neste artigo não procurarei propriamente dar resposta à pergunta que ficou ali, caída, por entre tudo o que se lhe seguiu e que incluiu outras experiências partilhadas, algumas lágrimas e uns cravos vermelhos lançados para cena em gesto de reconhecimento. O que me tem interessado reflectir é sobre este espaço comunitário de possibilidades, de troca, de encontro intergeracional - de confronto, por vezes, e de possibilidade de reconciliação, por outras - que Um Museu Vivo criou, nas breves apresentações que teve em Lisboa, Almada e Porto - na sua versão completa - e em Montemor-o-Velho, Covilhã e Bragança - na sua versão redux.

Paralelamente, Um Museu Vivo tem, acredito, ampla matéria de reflexão a partir da relação que nele se estabelece entre teatro e memória (e história), bem como das suas metodologias 
e formato de apresentação, que talvez possam ser, afinal, aproximações a uma resposta à pergunta de partida deste artigo. E digo aproximações pois, na verdade, não creio que aquilo que aquele homem procurava fosse verdadeiramente uma resposta, mas sim a possibilidade de perguntar e de se colocar num espaço de encontro e reflexão, tal como é entendido por Della Pollock: «[um] espaço reflexivo particularmente carregado, contingente de encontro da complexa rede das nossas histórias respectivas [que] pode, pois, atrair os participantes para entendimentos novos e renovados do passado» (Pollock, 2005: 1). Esse era precisamente o lugar daquele debate que levámos a cabo todas as noites, depois de quatro horas e meia de espectáculo e, na maioria das vezes, para a quase totalidade da sala que tinha assistido ao espectáculo (quando o que seria expectável e compreensível é que as pessoas preferissem sair logo depois de tão longa récita). Não sendo um lieu de mémoire ${ }^{1}$ no sentido que Pierre Nora (1996) definiu (mais um milieu ${ }^{2}$, talvez), mas tendo como ponto de partida a investigação sobre múltiplos desses lieux, o espectáculo constitui-se não obstante como um acontecimento «denso», no sentido em que Clifford Geertz (1973) definiu esta densidade na sua abordagem a uma etnografia do presente que olhe para a realidade como um manuscrito «estranho, desvanecido, cheio de elipses, incoerências, emendas suspeitas e comentários tendenciosos» ${ }^{3}$ (idem, 10), e no sentido em que Alessandro Portelli define o acto dialógico da entrevista de história oral (2013), que completa com a expressão «troca profunda» («deep exchange») (1997). Neste lugar de uma «comunidade imaginada» (Anderson, 2006) dos que experienciaram directamente e dos que não experienciaram os acontecimentos e os momentos históricos que ali se tratavam, aconteceu um estranho e raro momento em que a performance se propôs cumprir a sua promessa de espaço de possibilidades, de alternativa. 
Um Museu Vivo de Memórias Pequenas e Esquecidas decorre de um processo de investigação doutoral em que me propus estudar formas de transmissão da memória política em Portugal, com referência a três momentos/acontecimentos concretos: a(s) ditadura(s) portuguesa(s) - militar, Nacional e Estado Novo (1926-1974) o 25 de Abril de 1974 e o processo revolucionário que se lhe seguiu, durante 19 meses, conhecido pelo epíteto, normalmente de uso pejorativo, de PREC, ou Processo Revolucionário em Curso (1974-1975) ${ }^{4}$. Esta investigação - em que a prática é, ela própria, pesquisa - teve sempre como objectivo a construção de um espectáculo teatral, cujo formato não me foi desde logo evidente, mas que se foi desenhando numa ligação orgânica entre teoria e prática, à medida que me propunha participar em diversos congressos científicos, apresentando os progressos da minha investigação sob forma de palestras performativas 5 . Este mesmo acabou por ser o formato final de Um Museu Vivo, uma performance que se organiza em torno de sete palestras performativas e um prólogo, seguindo uma cronologia linear desde a ditadura militar de 1926 até aos nossos dias.

$\mathrm{Na}$ origem deste projecto está a dialéctica proposta por Diana Taylor (2003) entre o «arquivo» e o «repertório» enquanto formas de personificação («embodiment») da memória e sua transmissão. Taylor escreve:

The rift, I submit, does not lie between the written and spoken word, but between the archive of supposedly enduring materials (i.e., texts, documents, buildings, bones) and the so-called ephemeral repertoire of embodied practice/knowledge (i.e., spoken language, dance, sports, ritual).

(2003: 19) 25 de Abril de 1974. No entendimento que proponho em Um Museu Vivo, ao golpe militar sucede-se de imediato a sua apropriação pela população, que o transforma num amplo movimento popular. Uma parte da historiografia situa o PREC no período que se segue ao 11 de Março de 1975, no qual se assistiu ao que tem sido descrito como uma «radicalização» do processo revolucionário (importaria analisar com cuidado e detalhe esta leitura, mas isso ultrapassa o âmbito deste artigo). Este período tem o seu fim com o golpe de 25 de Novembro de 1975, que representa o que é geralmente entendido como a passagem para a «normalização democrática». Dulce Freire e Sónia Vespeira de Almeida introduzem um interessante número da revista Arquivos da Memória (2002), em que explicam a génese do acrónimo PREC: «A partir de 1975 vulgarizou-se a utilização da sigla PREC. A génese da abreviatura [...] parece estar associada à necessidade de nomear de forma sintética as múltiplas e rápidas mudanças que se seguiram ao golpe de estado de 25 de Abril de 1974. A sigla surgiu na imprensa e entre os protagonistas militares e políticos. E generalizou-se à população que andava a fazer a revolução nas ruas, nas escolas e universidades, nas várias instituições, nos quartéis, nas empresas, nos campos» (11). 
Taylor expõe claramente a hierarquização que subsiste a esta forma de entendimento da transmissão da memória, na qual o arquivo material detém, indiscutivelmente, a primazia nomeadamente nas civilizações ditas «ocidentais», concluindo: «o arquivável, desde o início, detém poder» (ibidem). No entanto, Taylor assume também a dificuldade de reduzir inteiramente a transmissão da memória a um ou a outro formato/ /dispositivo, afirmando:

they usually work in tandem and they work alongside other systems of transmission - the digital and the visual to name two. Innumerable practices in the most literate societies require both an archival and embodied dimension.

(idem, 21)

Mais ainda, Taylor assume uma posição crítica face nomeadamente à produção historiográfica que sistematicamente separou o «arquivo» do «repertório», materializada na polarização entre história e memória. Assumir também uma posição purista face ao «repertório» e à sua transmissão, como se fosse um sistema não-mediado, puro ou mais «verdadeiro» do que o arquivo, seria também incorrer numa armadilha, e creio que Taylor também se demarca claramente disso. Afinal de contas, há múltiplos sistemas de poder associados à transmissão quer da memória, quer da história - e isso é muita da matéria com que se constrói Um Museu Vivo.

Os estudos da memória, que proliferaram a partir da força memorial decorrente do fim da Segunda Guerra Mundial e do Holocausto - nomeadamente dos seus sobreviventes - são acompanhados de perto pela emergência do pós-modernismo na disciplina histórica, que questiona o lugar da verdade e a sua existência ${ }^{6}$, e desconstrói a história como uma «série de discursos sobre o mundo» (Jenkins, 1991: 6). Não seria o suficiente para que a história olhasse para a memória como sua aliada, como Hodgkin e Radstone referem (2003), embora, e ainda segundo estas autoras, trabalhar com o conceito de memória - «provisória, 
subjectiva, relacionada com a representação e com o presente, e não com os factos e com o passado» (ibidem, 2) - possa ajudar a superar o «impasse em que a historiografia se encontra», depois do «assalto à verdade» imposto pelo pós-estruturalismo (ibidem, 2). A barreira disciplinar entre memória e história seria quebrada através da história oral, de difícil afirmação junto dos seus pares da historiografia (Hobsbawm chamar-lhe-á «história vista de baixo» [1997: 206]), mas com um corpus de investigação consistente e profundo desde finais dos anos 6o. A história oral, e os estudos sobre a memória, enfatizam uma relação com a sua matéria - a memória das pessoas - que não é fixa nem definitiva e que, como o «repertório» de Taylor, não pressupõe que aí resida uma «verdade» - pelo menos não única e inquestionável. A crítica de Hobsbawm sobre a história oral ser memória pessoal e esta ser um meio pouco «fiável» para a preservação de factos - pois, tal como afirma nesta «não se trata tanto de uma gravação mas de um mecanismo selectivo, e a selecção está dentro de limites que estão sempre a mudar» (idem, 206) - é precisamente a questão distintiva desta disciplina: o reconhecimento de que a natureza da memória - o seu objecto de estudo - é a de estar em permanente «processo» (Hodgkin e Radstone, 2003: 4). E este processo não diz somente respeito ao indivíduo e às decisões que ele ou ela tomam quanto àquilo de que se devem lembrar e como: ele está ligado, a um nível mais profundo, à memória colectiva (Halbwachs, 1992), socialmente transmitida, e aos mecanismos de poder que condicionam, apagam, refreiam ou propagam essa memória. Como Hodgkin e Radstone concluem: «a história e a memória não são forças abstractas: localizam-se em contextos, instâncias e narrativas específicos, e é preciso decidir sempre que história se vai contar» (2003:5).

$\mathrm{O}$ meu interesse pelas formas de transmissão da memória inscreve-se, no contexto de Um Museu Vivo, no âmbito do questionamento das políticas públicas da memória em Portugal, e a forma como tem sido gerido o legado histórico e memorial da ditadura e da revolução nestes últimos quarenta anos. Como José Gil tão brilhantemente argumentou (2005 [2004]), Portugal padece de uma «falta de inscrição», uma «não-inscrição» do seu passado recente no espaço público, uma «não-inscrição» que se estende à própria existência como um todo, causa de um «trauma inaugural» (idem, 135), fruto de um «salazarismo» que não dava espaço a que essa inscrição se efectivasse, já que, «atolada num mal difuso e 
omnipresente, a existência individual não chegava sequer à tona da vida» (idem, 17). Esta não-inscrição não é passado - apesar de a sua origem se localizar no passado-é, sim, presente, num «prolongamento» do antigo regime porque:

inscrever implica acção, afirmação, decisão, com as quais o indivíduo conquista autonomia e sentido para a sua existência. Foi o Salazarismo que nos ensinou a irresponsabilidade - reduzindo-nos a crianças, crianças grandes, adultos infantilizados.

$(\text { ibidem })^{7}$

Recentemente, um conjunto de artigos num volume editado por Manuel Loff, Filipe Piedade e Luciana Castro Soutelo (2015) vem colmatar a falha de uma verdadeira reflexão sobre esta matéria, que ultrapassa a temática da justiça transicional, essa sim, alvo de algumas obras nos últimos anos. ${ }^{8}$ No artigo inicial que abre a obra, Manuel Loff traça um aturado retrato das políticas da memória em Portugal, desconstruindo discursos políticos e comemorações oficiais ao longo dos últimos quarenta anos, bem como analisando alguma da produção historiográfica em torno destas matérias. Existem dois grandes eixos na produção de história e memória com relação ao nosso passado recente - um diz respeito à memória da ditadura e outro à memória da revolução-, e estes eixos são centrais em Um Museu Vivo. De que maneira são estas memórias transmitidas e por quem?, como circulam no espaço público?, qual a ausência ou presença de inscrição e as formas dessas memórias? e como é feita a sua apreensão pelos sujeitos comuns - que não os grandes protagonistas de uma história até hoje fortemente dominada pelos actores militares e políticos? foram algumas das minhas perguntas de partida.

As formas e métodos de abordagem para a transmissão da memória de cada um dos acontecimentos/períodos aqui estudados diferem e obedecem a estratégias claras, com óbvia relação com cada governo no poder à data das comemorações oficiais, por exemplo, do 25 de Abril, que leva Miguel Cardina a escrever ironicamente num artigo no Expresso em 2010: «Não há curva de Abril para Maio que não nos mostre a dificuldade da direita em lidar com o momento revolucionário inaugurado pelo 25 de Abril.»

Quanto à memória da ditadura, Loff refere: 
qualquer observador esperaria, à partida, encontrar comportamentos por parte do estado relativamente à representação do passado autoritário - isto é, políticas públicas da memória - muito mais empenhadas na construção de uma memória descomplexada relativamente ao passado. Isso significaria que o estado português reclamaria como sua uma perspectiva geral do passado recente que pudesse ser apresentada como crítica democrática do autoritarismo, e, especificamente, da experiência autoritária portuguesa de 1926-74. Mas não é, e quase nunca foi, o que se verifica.

(idem, 25)

Loff verifica, com espanto, que a relação que existe com o passado ditatorial português é semelhante à dos regimes que não viveram processos de ruptura - como uma revolução, que é o caso português - tendo, sim, experienciado transições graduais, como os casos espanhol e brasileiro (ibidem). Sem dúvida, e conclui ainda Loff, «a polarização inevitável que o processo revolucionário introduziu na sociedade portuguesa dificultou o enraizamento social e político de consensos mínimos sobre a memória da ditadura» (idem, 32).

Esta «polarização inevitável», que não é só entre esquerda e direita, mas também entre as diferentes «esquerdas», introduziu ainda outra terrível incapacidade que é a de se gerar uma leitura ampla, abrangente, generosa mesmo, que não «exoticizada» (Godinho, 2015), extremada, preconceituosa - e amplamente construída por narrativas negativas reiteradas ao longo deste últimos quarenta anos - do processo revolucionário português, que teve lugar na sequência do 25 de Abril de 1974. Bastaria, para isso, abrirmos a edição de um qualquer jornal português desde que tiveram lugar as eleições de 4 de Outubro de 2015, para confirmarmos isto mesmo. A proliferação de artigos e comentários negativos contendo a palavra PREC e comparando a situação presente a esse período, procurando com isso inculcar nas pessoas um receio irracional - assente precisamente na construção negativa que se fez dessa época ao longo dos últimos quarenta anos - é tamanha, que a citação de todos me levaria a esgotar rapidamente o número de palavras atribuído a este artigo, e por isso cito somente uma passagem de um emblemático discurso do então vice-primeiro-ministro, Paulo Portas, num jantar com militantes do CDS-PP no dia 30 de Outubro de 2015: 
O CDS esteve do lado da democracia quando aconteceu o PREC. O CDS está do lado da democracia perante esta tentativa que às vezes parece um PREC 2. Da primeira vez, em 1975, eles diziam que a legitimidade revolucionária era mais importante do que esse detalhe, que era o voto dos portugueses. Os democratas uniram-se, o voto dos portugueses prevaleceu. Em 2015, o que está em causa saber é se o voto dos portugueses prevalece face a tentativas de secretaria de contrariar o voto dos portugueses. ${ }^{9}$

Este acontecimento, o PREC, como lugar de memórias conflituantes e como lugar de mistificações, é uma chave para o entendimento do próprio presente português. Porque, ao esvaziar-se de sentido e de significado um momento potenciador da acção política popular - um espaço de possibilidades, como foi o PREC (não obstante, e por ter trazido consigo a torrente inevitável das vontades todas à solta, num povo sem tradição anterior recente de mobilização popular naquela escala e com o legado de quarenta $\mathrm{e}$ oito anos de despolitização, analfabetização, forçados «brandos costumes» e «pobreza honrada») - esvazia-se também de sentido qualquer tentativa presente de uma verdadeira e abrangente mobilização social - como se assiste de forma reiterada em países como a Grécia ou Espanha. «Para quê?», diz-se, «não vale a pena, eles...» Eles (diferentes do eles de Paulo Portas), este ser omnipresente que representa os que decidem, os políticos. Como José Gil refere, «o discurso político tornou-se dominante na vida portuguesa. Num certo momento ele transvazou para a sociedade civil, identificando todo o poder com o poder político» (2005: 18).

Num artigo por altura do trigésimo aniversário do 25 de Abril em 2004, que teve como slogan base das suas comemorações oficiais o fracturante «Abril é Evolução», Luís Trindade escreve: «Trinta anos depois é praticamente impossível pensar o 25 de Abril» (2014: 21). Este artigo significativo questiona o lugar da revolução na narrativa portuguesa de brandos costumes e passividade - uma narrativa também ela interiorizada e mimeticamente reproduzida em gestos e hábitos diários, confirmando em absoluto o sucesso da inculcação ideológica da construção do Estado Novo desse homem novo, «regenerado», fruto da sua «revolução de mentalidades», cuja extensão total na nossa sociedade presente faltará ainda aferir (apud Torgal, 


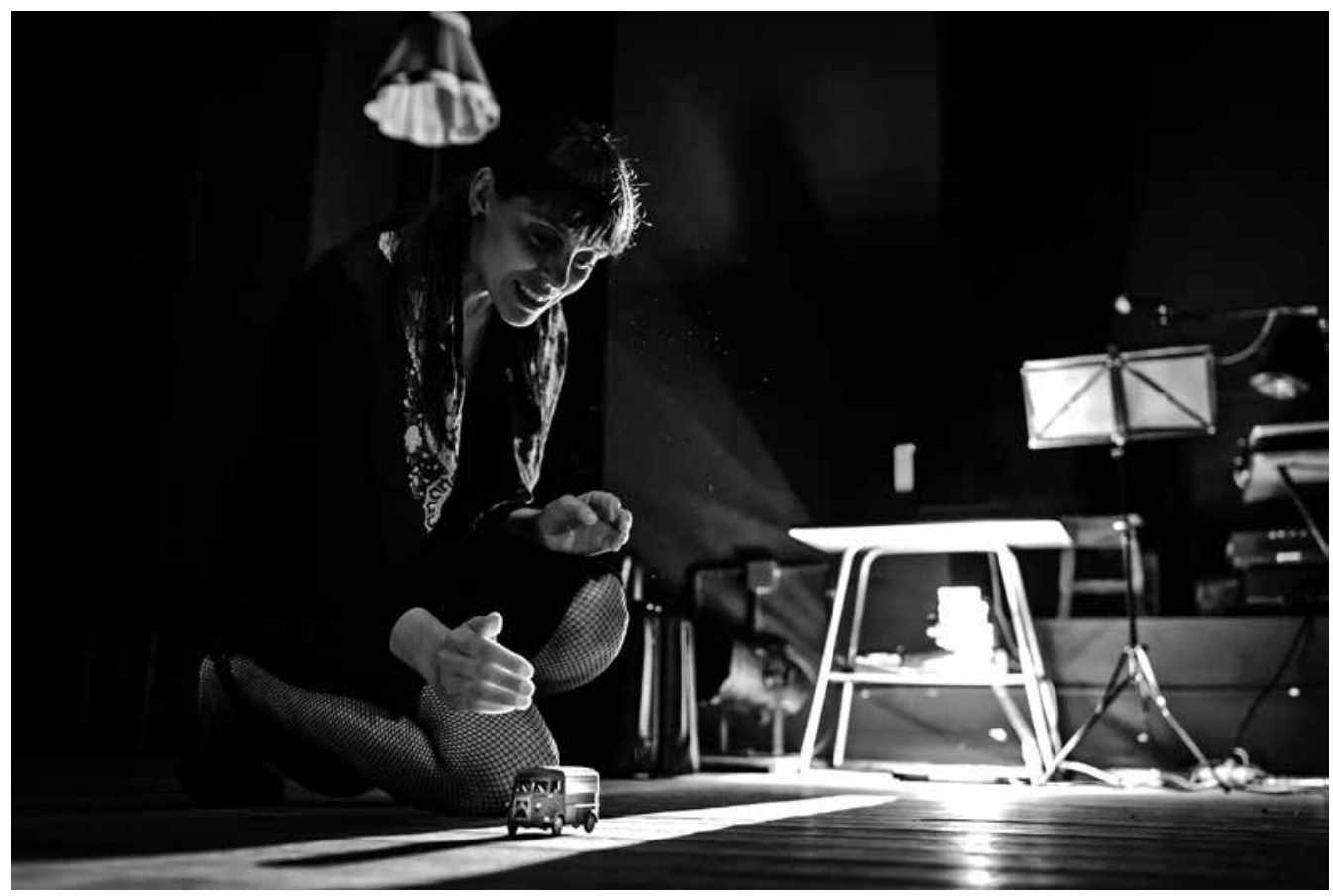

UM MUSEU VIVO DE MEMÓRIAS PEQUENAS E ESQUECIDAS, DE JOANA CRAVEIRO, TEATRO DO VESTIDO, 2015 (JOANA CRAVEIRO), [F] JOÃO TUNA
2009). Eduardo Lourenço afirmou que houve uma implantação «orgânica» (1976: 332) do fascismo português na sociedade, nas pessoas, num livro que, de forma premonitória, intitulou O Fascismo nunca Existiu. Hoje, já dificilmente se pode utilizar a palavra fascismo, substituída que foi no entendimento que as progressivas revisões foram fazendo daquilo que nos aconteceu (a ditadura) - e incluo-me nesse entendimento, porque sei que vivo de variadas formas com esse legado, consciência que, de certa forma, motivou a pesquisa para Um Museu Vivo, tal como expresso num excerto de abertura da primeira palestra, «Pequenos Actos de Resistência»:

Tudo começou para mim quando eu me perguntei como é que uma ditadura podia ter durado tanto tempo, e me fiz a pergunta mesmo concreta: mas de onde é que eu venho afinal? Era como perguntar, quem sou eu?, O que é que disto resta em mim?

(Craveiro, 2015: 4)

Sobre esse momento de ruptura, de quebra de paradigma, que foi a revolução, Trindade escreve: 
Como pensar o povo português na rua, tomando decisões, debatendo-se, organizando-se, inventando, subvertendo? Como encarar de frente, no essencial, o único momento da contemporaneidade portuguesa em que a sociedade fez política? Ou seja, assim sendo, com que ferramentas ler esse fugaz momento em que a existência em Portugal foi vivida numa densidade moderna?

(2014: 26)

\section{E conclui:}

O 25 de Abril surge então na nossa modernidade como uma estranheza, talvez o único momento em que as instituições e a estrutura social foram postas em causa por uma agitação transformadora que os discursos sempre tinham garantido não fazer parte da natureza do povo português. [...] o PREC, que deixou mais ou menos incólume, a prazo, a estrutura social, manchou a narrativa política portuguesa.

(idem, 31)

Seria moroso analisar aqui toda a complexidade dos processos de memória, obliterações e hegemonias várias ${ }^{10}$ que leva a esta amnésia fundamental do espectro potenciador do PREC, e teríamos de acrescentar ao processo de «normalização democrática» pós-25 de Novembro, que obrigou a um apagamento do momento anterior ${ }^{11}$, também as clivagens que já aqui referi dentro da própria esquerda, que levam a que também não se possa estabelecer uma memória consensual, ou suficientemente forte, ao ponto de se impor a outras memórias que pretendem inscrever uma reinscrição desse período no próprio espaço de memória pessoal dos indivíduos. A isso atribuo os silêncios envergonhados com que alguns dos meus entrevistados pautaram as suas memórias do PREC, por contraste com outros que, livremente, rememoraram esses acontecimentos quase como se cometessem uma infracção consciente sobre as memórias dominantes - e disso se orgulhassem. 
Como refere Paula Godinho, «falar e escrever acerca de revoluções e revolucionários não está na moda» (Godinho, 2011: 16).

\section{OUTRAS HEGEMONIAS}

Foi neste questionamento da dicotomia histórica entre vencedores e vencidos, entre memórias dominantes (fortes) e memórias ditas fracas (Traverso, 2012; Godinho, 2015), que decidi metodologicamente trazer para a investigação de Um Museu Vivo os métodos de trabalho de campo da antropologia e etnografia (que incluíram desde sempre a recolha de histórias de vida), em combinação com a história oral, que utiliza as fontes orais como matéria primordial de investigação histórica. Procurei conduzir entrevistas em profundidade, com pessoas que tivessem experienciado acontecimentos relacionados com a ditadura e com a revolução. O meu trabalho incide essencialmente sobre memórias de resistentes e de esquerda (de várias esquerdas), e com isso pude descobrir e problematizar os próprios discursos hegemónicos dentro da esquerda, por contraponto a discursos que correspondem a memórias fracas, que não encontraram implantação no espaço público memorial da revolução, por exemplo - e também não do da resistência à ditadura, no seu período final. Como é do senso comum, e comprovado historicamente, o maior movimento de resistência antifascista em Portugal foi o Partido Comunista Português (PCP). A partir de cerca de 1964, contudo, novos grupos políticos e ideologias de resistência começam-se a desenhar - algumas delas a partir de dissidências dentro do próprio PCP, que em parte se devem à ruptura sino-soviética, que deu origem à emergência das ideologias marxistas-leninistas e maoístas. Irão desempenhar um papel importante na fase final do regime, e serão também alvo de uma escalada de repressão, muito centrada nos estudantes universitários, grupo génese de muitos destes movimentos. São também estes grupos que, de forma constante e desde a sua fundação, realizam uma oposição aberta à Guerra Colonial. As memórias e a memória destes movimentos, contudo, aglutinada nas amálgamas dos «revolucionários», «esquerdalhos», «esquerdistas», perderam-se da história dominante e das outras histórias mais ou menos privadas, tendo sido recentemente recuperadas pelo trabalho historiográfico 
exemplar de Miguel Cardina (2011), e os trabalhos de memória e sua análise de Paula Godinho e António Monteiro Cardoso (2011). Há ainda a referir o trotskismo, que Um Museu Vivo aborda igualmente em «Fragmentos de Um Processo Revolucionário», a quarta palestra performativa.

É curioso referir o desconforto com que alguns dos testemunhos que relatei em Um Museu Vivo foram recebidos por segmentos do público, que ora me apelidava de «esquerdista» nos debates pós-espectáculo, ora me fazia saber que «a primeira parte do espectáculo era melhor do que a segunda» - talvez porque na primeira parte o foco estivesse mais sobre uma versão mais hegemónica (ou mais consensual) da resistência antifascista (o PCP, com excepção dos episódios que dizem respeito a Aurora Rodrigues $^{12}$, Francisco Martins Rodrigues ${ }^{13}$ e Ribeiro Santos ${ }^{14}$, este último, no entanto, uma figura consensual junto das esquerdas, pela simbologia da luta antifascista de que se revestiu o seu assassinato por um agente da PIDE em 1972).

\section{PÓS-MEMÓRIA}

Este interesse pelo processo de produção de memórias e narrativas e a sua conflitualidade advém provavelmente da minha condição de não ter experienciado nenhum dos momentos que investiguei directamente - a não ser as poucas memórias do pós-PREC que relatei no espectáculo, bem como memórias dos anos 80 (o «meu» fim da revolução) e das recentes comemorações do 25 de Abril em 2014. Ao pôr-me de fora dos acontecimentos, lugar onde naturalmente estou, enquanto testemunha póstuma que recebeu esta memória em primeiro lugar via transmissão familiar - e sem recolhido e editado por Paula Godinho e António Monteiro Cardoso. Foi presa pela PIDE em 1973, sujeita a dois períodos contínuos de tortura do sono, de dezasseis e quatro dias. fuga da prisão de Peniche, juntamente com Álvaro Cunhal e Francisco Miguel, entre outros, e em 1962 fazia parte da Comissão Executiva daquele partido). Distanciou-se da linha de actuação do PCP face sobretudo à Guerra Colonial e à necessidade de radicalização da luta revolucionária. Criou o Comité Marxista-Leninista Português (CMLP) e a Frente de Acção Popular (FAP), com Rui d'Espiney e João Pulido Valente, em Paris, em 1964. Foi preso pela PIDE pela última vez em 1966 e torturado de diversas formas, tendo sido libertado só depois do 25 de Abril. Para uma história da sua vida e ideias políticas, ler Martins Rodrigues $(2008,2009)$. 
qualquer preocupação com a chamada «objectividade», algo em que, aliás, não acredito -, pude, não obstante, observar com mais clareza algumas das formas de produção de discursos e narrativas sobre estes acontecimentos, tornando isso parte das problemáticas abordadas/representadas em Um Museu Vivo. Marianne Hirsch descreveu a condição de uma «segunda geração», que não experienciou directamente os acontecimentos, como sendo a de uma «pós-memória» (2008), que descreve essencialmente o que Hirsch considera uma qualidade (2012: 4). Recebida por via familiar, intergeracionalmente, esta memória é o que me permite ter emoção face a cravos vermelhos, sem nunca ter vivido directamente 025 de Abril de 1974; é o que permite à minha amiga Rita, que nasceu depois de mim, dizer que «ainda hoje se emociona com a "Grândola" (uma frase onde parece faltar o início, «como naquele dia», mas que não falta realmente, porque ela não esteve lá); ou de a mesma Rita ter na parede, emoldurado, um jornal do dia 25 de Abril cujo título se refere ao golpe das Forças Armadas; é o que nos permite a todos os que descemos a avenida da Liberdade, em Lisboa, a cada dia 25 de Abril, sentirmos que aquela memória também é nossa ou, pelo menos, não estarmos preocupados se estávamos ou não lá nesse dia, porque hoje estamos, e isso basta. Ainda hoje nos emocionamos.

Escrevendo sobre o teatro que foi/é feito na Argentina depois do fim da ditadura militar de 1976-1983, Brenda Werth pergunta:

What are the implications and expectations of inheriting a complex, traumatic past on both an individual and a collective level, and what are the creative approaches available to the younger generation in reconstructing the past and imagining present and future identities linked to, but not dominated by, the past?

(2010: 173)

A pergunta é pertinente e aplicar-se-ia a Portugal e às suas gerações da pós-memória, se tivéssemos consciência do nosso passado como «complexo e traumático» - não o da revolução, como algumas narrativas que já aqui expus tentam fazer passar, mas o da ditadura, com todo o seu aparato repressivo e profundamente condicionador do pensamento, da cultura, da liberdade - de que somos inevitavelmente herdeiros, como também aqui referi. Temos, em comparação com a Argentina, uma relação muito diferente com o nosso passado «complexo e 
traumático». Em países como a Argentina e o Chile, herdeiros de um passado ditatorial brutal e sobretudo reconhecido como tal, os locais de memória são valorizados, transformados em memoriais, e há movimentos por parte das gerações da pós-memória que se propõem mapear os locais de terror e de tortura e identificar os torturadores. ${ }^{15}$ É bem diferente de ter o edifício que foi sede da polícia política (PIDE/DGS) transformado em condomínio de luxo, em pleno coração da capital do país, sem uma placa memorial estatal que identifique sequer a sua utilização passada. ${ }^{16}$ É também bem diferente da relação que temos com um passado que nos é servido de forma comodificada em vídeos depois do telejornal e sustentados pelas narrativas paralelas de demonização do PREC e suavização da memória ditatorial.

Neste contexto, é surpreendente que se assista desde, pelo menos, o início desta década a um romper dos silêncios e de algumas narrativas por uma série de obras artísticas criadas por membros desta geração da pós-memória, com um olhar que, de fora, se questiona sobre o dentro - que é o agora. Criar uma obra artística sobre estas matérias hoje é falar inevitavelmente da nossa relação com isso e da relação da sociedade portuguesa com isso, e questionar o sistema construtor das narrativas, que estas obras, em meu entender, tentam confrontar. Falo, por exemplo, de 48 , de Susana de Sousa Dias; de Linha Vermelha, de José Filipe Costa; da obra de Filipa César; de $O$ Medo à Espreita, de Marta Pessoa; falo das peças Três Dedos abaixo do Joelho, de Tiago Rodrigues; de Coragem hoje, Abraços amanhã, de Joana Brandão; de Não Falarei nem Que Me Matem, de Marta Freitas; de Um Dia os Réus Serão Vocês, de Rodrigo Francisco. Como referi, são alguns exemplos, parte do que podemos intuir como movimento mais amplo e que tem, sem dúvida, um paralelo na produção académica dessa mesma geração dita da pós-memória. a utilização presente da ESMA (Escuela Superior de Mecánica de La Armada), antigo local de detenção e tortura durante a ditadura argentina. 
TRANSIC̣ÕES

Em 1980, Kenneth Maxwell, historiador norte-americano que investigou a fundo a revolução portuguesa e a consequente passagem para a democracia, confirma o que parece ser uma transmutação de valores de um regime para outro (com passagem por esse campo de possibilidades que foi a revolução):

Despite the formidable transformations set in motion by April 25, 1974, however, much in Portugal did not change. The social composition of the new political class differs very little from that of the old regime. [...] Workers whose purchasing power temporarily increased after 1974, might have marched in demonstrations and chanted slogans of socialist revolution, but they spent their money on the clothes, appliances, and artifacts of West European consumer societies, whose standard of living they aspired to. The white-collar workers, in particular, who had been among the most vociferous "leftists" in 1975, moved quickly to the right as economic conditions worsened. In behaviour and psychology, it is not yet clear how much really changed in Portugal beyond the traumatic recognition, as revolutionary optimism evaporated, of the resilient power and divisiveness of class, regional, and personal antagonisms and jealousy.

(s. d.: 44)

Na geração da pós-memória, de que faço parte, lidámos desde sempre com este «desaparecer progressivo» das marcas da revolução dia após dia, como nos murais apagados das ruas, ou os livros ditos «revolucionários» retirados das estantes e guardados num qualquer canto de difícil acesso (como descrevi em Um Museu Vivo). Lidámos com a memória que não temos desse tempo que não chegou totalmente a ser, e que, ainda por cima, nos dizem que talvez nem devesse ter sido - afinal de contas, e segundo uma outra narrativa, Marcello Caetano estaria a preparar a «transição na continuidade», e Espanha assim o fez e, quem sabe, melhor que nós, pelo menos sem «convulsões», assim se vai lendo nas entrelinhas. Registei, por exemplo, com interesse, as notícias em torno da morte de Adolfo Suárez, o primeiro-ministro que sucedeu à morte do general Franco. ${ }^{17}$ As notícias pareciam valorizar claramente este carácter de transição sem sobressaltos, como foi a transição espanhola da ditadura para a democracia - que criou, como está hoje amplamente estudado, falsos consensos ancorados 
numa política de silêncio, que sublimou os traumas, mas não os fez desaparecer, como por exemplo Paloma Aguilar estudou (2001).

Talvez por isso, como reacção a Um Museu Vivo, uma espectadora pouco mais velha do que eu (teria talvez cinco ou seis anos à data da revolução) me tenha dito que naquele dia se tinha «apercebido da vergonha» que sentiu da revolução, que foi algo que não sabe como explicar, mas que se foi instalando-depois «daquilo» ficou um vazio, um embaraço. Outra espectadora, mais ou menos da idade da anterior, agradeceu-me por «tê-la reconciliado com estas memórias». Recordei-me, por contraponto, de alguns moradores dos bairros $\mathrm{SAAL}^{18}$ do Porto que entrevistei, e da alegria com que contavam as suas memórias, em particular uma mulher, que na altura tinha cinco anos e que se lembra de tudo, que me dizia: «Democracia?! Mas acha que estes políticos [de hoje] fazem alguma ideia do que é a democracia?»

Efectivamente, Portugal não viveu uma transição, mas sim uma ruptura - chamou-se revolução porque foi isso que efectivamente foi. Começou por ser um golpe militar, que rapidamente evoluiu para um golpe/sublevação popular, como John Hammond descreve: «Em Portugal, em 1974 e 1975, pessoas comuns desafiaram a ordem social de forma vigorosa, transformando um golpe militar numa tentativa de revolução» (1988: 9).

Pretender, portanto, forçar memórias consensuais sobre o 25 de Abril é esquecer o propósito fundamental de um golpe que se fez, de facto, contra alguns portugueses: os que governavam um regime ditatorial ou que o sustentavam por forma do seu colaboracionismo (que em Portugal era assegurado por uma ampla rede de informadores, muitos deles responsáveis por prisão e tortura de dezenas de pessoas). A ausência de um verdadeiro processo de justiça transicional - cívico, participado, que tivesse deixado na população a certeza de ter havido justiça - permite que estes consensos forçados sejam impostos sobre um acontecimento que nunca será «evolução», porque ele foi, de facto, uma «revolução». E ambos são bem diferentes. 
UCRONIAS E POSSIBILIDADES

O que expus até aqui, apesar de parecer distante de uma análise do espectáculo teatral Um Museu Vivo, é, como o título deste artigo encerra, o seu «pensamento e processo». Quando me propus construir um Museu e criei a persona Arquivista (a narradora/ /curadora/documentarista) deste $\mathrm{Museu}$, usei conscientemente uma palavra que remete para o arquivo de Taylor, o museu: esse lugar de produção hegemónica de uma história oficial e sua apresentação/disseminação; e usei uma figura também de autoridade de conhecimento e de mediação: a arquivista. Mas, por me propor construir um espectáculo teatral, assente nessa relação particular com o testemunho e com a participação do próprio público (em momentos chave do espectáculo, assim como no debate final), aquilo que Um Museu Vivo opera é a interpelação do arquivo pelo repertório e vice-versa, é a própria transmutação do arquivo em repertório - equação aliás já presente no próprio título do espectáculo: o museu é «vivo», as memórias são «pequenas e esquecidas». Mais, o espectáculo não só reflecte sobre formas de transmissão da memória - ele próprio transmite memória.

Faltará, por esta altura, abordar o que ficou suspenso como promessa na introdução ao artigo: o domínio da possibilidade que Um Museu Vivo introduz. A possibilidade de que falo refere-se a vários episódios, que já aqui expus, de interpelações por parte do público e seus comentários e os diferentes significados que essa interpelação (ou a sua possibilidade) encerra.

Em primeiro lugar, a possibilidade da transmissão e do conhecimento partilhado - naquilo que apelidei um esforço de «reconstituição» (que, aliás, desafio os espectadores a continuarem a realizar comigo, mesmo depois do fim do espectáculo, e cuja primeira etapa em meu entender se cumpre no debate final). Como Taylor escreve: «o repertório requer presença: as pessoas participam na produção e na reprodução de conhecimento “estando lá", fazendo parte da transmissão» (idem, 20).

Em segundo lugar, a possibilidade da escuta de vozes e memórias silenciadas, não só pelo ruído da história hegemónica, que já aqui abordei, mas pelo silêncio da não-inscrição que se traduz em silêncios múltiplos - por exemplo, não só dos condenados pelos tribunais plenários e torturados pela PIDE, como os silêncios dos ex-combatentes na Guerra Colonial, o silêncio dos que falaram na PIDE e a destruição que esse acto operou sobre 
a vida de alguns deles, constituindo uma clara vitória do regime naquilo que era o seu propósito fundamental de despersonalização e destruição da subjectividade política do preso $^{19}$; como também os silêncios de uma história da revolução de que ninguém gosta de falar; como ainda os silêncios dos que retornaram das ex-colónias (silêncio esse que vem sendo cada vez mais quebrado no espaço público desde a estreia da série Depois do Adeus $(2013)^{20}$, que não vou agora aqui analisar).

Em terceiro lugar, a possibilidade da contestação ao vivo, da refutação, da correcção das memórias por mim representadas, numa lógica sem dúvida desafiante (para mim), mas que aprendi a cada apresentação ser parte inalienável deste processo, e que me competia obrigatoriamente criar resiliência para acompanhar e responder - mas sobretudo deixar acontecer.

Em quarto lugar, corolário de tudo o exposto antes, a possibilidade de reconciliação. Com reconciliação, não me quero referir a consensos fabricados ou impostos em nome da boa convivência, como já tive ocasião de argumentar. Refiro-me, sim, a uma dimensão reconciliatória que é a dos sujeitos com a sua própria história, no contexto das graves crises ideológicas dos últimos quarenta anos, potenciadas pela queda do Muro de Berlim e pela entrada em pleno funcionamento de um capitalismo feroz, neoliberalista e apagador de dissidências e alternativas - o mesmo neoliberalismo que produz um discurso de inevitabilidade sobre a ordem do mundo. A mesma ordem que os que viveram o período de 1974-75 pensaram - e muitas vezes conseguiram - desafiar. E em que:

without batting an eyelid at the enormity of what they were attempting, young revolutionaries (and older ones) talked seriously of a direct transition from fascism to libertarian communism. They acted as if belief in miracles could drive people to attempt - and, who knows perhaps even to achieve - the "impossible."

(Brinton, 1976: 22)

Não estamos aqui exactamente no domínio que Alessandro Portelli identificou nos discursos frustrados da resistência italiana do pós-guerra, em que havia uma dimensão «imaginária», fantasias políticas, que correspondiam acima de tudo a uma 
história que não é a que aconteceu, mas a que poderia ter acontecido - a que ele chamou «ucronia» (2013), e cujo domínio, dizia Portelli, era o da «possibilidade» (idem). Embora lidando com a frustração evidente das utopias perdidas, das batalhas perdidas, aquilo que Um Museu Vivo recupera é uma dimensão concreta, real, do que foi para aquelas pessoas aquele momento de revolução, de mudança concreta, legitimando a sua versão da história, «para além da ucronia» (furtando o título de uma significativa exposição de 2014 de João Baia, Catarina Laranjeiro e Marta Leite, que mostrava isto mesmo ${ }^{21}$ ). Como Portelli também refere, naquilo que descreve como uma «ética de restituição e amplificação» que precede o trabalho de história oral, «o serviço mais importante que prestamos às comunidades, movimentos ou indivíduos, consiste em amplificar as suas vozes e levá-las para fora, rompendo com a sensação de isolamento e impotência e fazendo com que o seu discurso chegue a outras pessoas e comunidades» (2013: 71). Na reencenação das memórias que Um Museu Vivo propõe, a memória enquanto campo de possibilidades permanece em constante construção, reescrita, adição.

É exactamente como Annette Kuhn descreve:

These stories may [...] heal the wounds of the past. They may also transform the ways individual and communities live in and relate to the present and the future. For the practitioner of memory work, then, it is not merely a question of what we choose to keep in our "memory boxes" - which bits and pieces, which traces of our own past, we lovingly or not so lovingly preserve - but of what we do with them: how we use these relics to make memories, and how we then make use of those stories they generate to give deeper meaning to, and if necessary, to change our lives now.

(2000: 186-187)

Um Museu Vivo cria, acima de tudo, um espaço - como qualquer museu cria. E um espaço era aquilo de que estas memórias precisavam - para se exporem, para se verem, para se ouvirem, para se perguntarem.

Não sei ainda que teatro é exactamente este. Socorro-me de Portelli mais uma vez, propondo que talvez seja um teatro «não apenas do que aconteceu, mas também do que não aconteceu e deveria ter acontecido» - um teatro «como alternativa» (idem, 74). 


\section{REFERÊNCIAS BIBLIOGRÁFICAS}

AgUilar, Paloma (2001), «Justice, Politics and Memory in the Spanish Transition», in Alexandra Barahona de Brito, Carmen Gonzaléz Enrriquez e Paloma Aguilar (ed.), The Politics of Memory and Democratization: Transitional Justice in Democratizing Societies, Oxford, Oxford University Press, pp. 92-118.

ANDERSON, Benedict (2006), Imagined Communities, Londres e Nova Iorque, Verso [1983].

BANDEIRINHA, José António (2014), O Processo SAAL e a Arquitectura no 25 de Abril de 1974, Coimbra, Imprensa da Universidade de Coimbra.

BRIN T ON, Maurice (1976), «Introduction», in Phil Mailer, Portugal: The Impossible Revolution, Londres, Solidarity, pp. 9-26.

CARDinA, Miguel (2010), «Abril e o Excesso», Expresso, 25 de Abril de 2010, http://expresso.sapo.pt/blogues/ blogue_aparelho_de_estado/abril-e-o-excesso=f578649, acedido a 10 de Novembro de 2015 .

-- (2011), Margem de Certa Maneira, Lisboa, Tinta-da-china.

-- (2013), «To Talk or Not to Talk: Silence, Torture and Politics in the Portuguese Dictatorship Estado Novo», Oral History Review, 6 de Agosto de 2013.

CARD oso, António Monteiro (2011), «Um tempo, um contexto», in Aurora Rodrigues, Gente Comum: Uma História na PIDE, Castro Verde, 10oLuz, pp. 45-56.

CONnerton, Paul (1989), How Societies Remember, Cambridge e Nova Iorque, Cambridge University Press. Craveiro, Joana (2015), Um Museu Vivo de Memórias Pequenas e Esquecidas, cópia de trabalho não editada.

FREIRE, Dulce e ALMEIDA, Sónia Vespeira de (2002), «Portugal 1974-1976. Processo Revolucionário em Curso - Apresentação», in Jorge Crespo (ed.), Arquivos da Memória - «Portugal 1974-1976. Processo Revolucionário em Curso», Centro de Estudos de Etnologia Portuguesa, n. ${ }^{\circ \mathrm{1}}$ 12/13, pp. 11-21.

GEERTZ, Clifford (1973), The Interpretation of Cultures, Nova Iorque, Basic Books.

GIL, José (2005) Portugal, Hoje: O Medo de Existir, Lisboa, Relógio D’Água [2004].

Godinho, Paula (2011), «História de Um Testemunho com Caxias em Fundo», in Aurora Rodrigues, Gente Comum: Uma História na PIDE, Castro Verde, 10oLuz, pp. 11-43.

-- (2015) «Passados Insubordináveis: Acontecimento, Razão Escrita e Memórias Fracas», in Manuel Loff, Filipe Piedade, Luciana Castro Soutelo (eds.), Ditaduras e Revolução: Democracia e Políticas da Memória, Coimbra, Almedina, pp. 145-167.

GRACiano, Sérgio e SEqueira, Patrícia (2013), Depois do Adeus, RTP1.

HAlbWachs, Maurice (1992), On Collective Memory, editado, traduzido e com introdução de Lewis A. Coser, Chicago, University of Chicago Press.

HAMmond, John (1988), Building Popular Power; Workers' and Neighborhood Movements in the Portuguese Revolution, Nova Iorque, New York University.

HENRIQUES, João Pedro (2014), «Um político sem coragem física e intelectual não é um político», entrevista a Mário Soares, Diário de Notícias, 24 de Março de 2014.

HiRSCH, Marianne (2008), «The Generation of Postmemory», Poetics Today, 29:1, pp. 103-128.

-- (2012), The Generation of Postmemory, Writing and Visual Culture After the Holocaust, Nova Iorque, Columbia University Press.

нов ваWм, Eric (1997), On History, Londres, Weinfeld \& Nicolson.

HODGKIN, Katharine e RADSTONE, Susannah (eds.) (2003), Contested Pasts, Londres e Nova Iorque, Routledge. JEN KINS, Keith (1991), Re-thinking History, Londres e Nova Iorque, Routledge.

KUHN, Annette (2002), Family Secrets: Acts of Memory and Imagination, Londres e Nova Iorque, Verso [1995]. LOFF, Manuel (2015), «Estado, Democracia e Memória», in Manuel Loff, Filipe Piedade e Luciana Castro Soutelo (eds.), Ditaduras e Revolução: Democracia e Políticas da Memória, Coimbra, Almedina, pp. 23-143.

LORENA, Sofia (2014), «Espanha despede-se do homem que tornou a democracia possível», Público, 23 de Abril de 2011.

LOURENÇO, Eduardo (1976), O Fascismo nunca Existiu, Lisboa, Publicações Dom Quixote.

MARTINS Rodrigues, Francisco (2008), Os Anos do Silêncio, Lisboa, Dinossauro Edições.

-- (2009), História de Uma Vida, Lisboa, Dinossauro Edições. 
MAXWELL, Kenneth (s. d.), «The transition in Portugal», working paper, Washington, DC, Latin American Program, Wilson Center.

NORA, Pierre (ed.) (1996), Realms of Memory: Rethinking the French Past, vol. 1: «Conflicts and Divisions», Nova Iorque, Columbia University Press.

PEREIRA, João Martins (1982), No Reino dos Falsos Avestruzes, Lisboa, A Regra do Jogo.

pimentel, Irene e Rezola, Maria Inácia (2013), Democracia, Ditadura: Memória e Justiça Política, Lisboa, Tinta-da-china.

POLLOCK, Della (ed.) (2005), Remembering: Oral History Performance, Nova Iorque, Palgrave.

PORTELLI, Alessandro (1997), The Battle of Valle Giullia, Londres, University of Wisconsin Press.

-- (2013), A Morte de Luigi Trastulli e Outros Ensaios, org. Miguel Cardina e Bruno Cordovil, Lisboa, Unipop. PÚBLICO/LUSA, http://www.publico.pt/politica/noticia/nao-ha-legitimidade-politica-para-a-esquerdaformar-executivo-diz-portas-1712930, acedido a 15 de Novembro de 2015.

Rodrigues, Aurora (2011), Gente Comum - Uma História na PIDE, Castro Verde, 10oLuz.

TAYLOR, Diana (2003), The Archive and the Repertoire, Nova Iorque, Duke University Press.

TORGAL, Luís Reis (2009), Estados Novos, Estado Novo, Coimbra, Universidade de Coimbra.

Traverso, Enzo (2012), O Passado, Modos de Usar. História, Memória e Política, trad. Tiago Avó, Lisboa, Unipop.

TRINDADE, Luís (2014), «Os Excessos de Abril», Revista História, n. ${ }^{65}$, Abril de 2014, pp. 20-31.

WERTH, Brenda (2010), Theatre, Performance, and Memory Politics in Argentina, Nova Iorque, Palgrave Macmillan. 